Bull. Mater. Sci., Vol. 22, No. 1, February 1999, pp. 25-32. (C Indian Academy of Sciences.

\title{
Studies on indentation fracture toughness on ceramic and ceramic composite using acoustic emission technique
}

\author{
A K RAY*, G DAS, N K MUKHOPADHYAY ${ }^{\dagger}$, D K BHATTACHARYA, E S DWARAKADASA \\ and N PARIDA \\ National Metallurgical Laboratory, Jamshedpur 831007 , India \\ 'Department of Metallurgy, Institute of Technology, Banaras Hindu University, Varanasi 221005 , India \\ ${ }^{\ddagger}$ Department of Metallurgy, Indian Institute of Science, Bangalore 560012 , India
}

MS received 18 July 1998; revised 23 November 1998

\begin{abstract}
This paper is aimed at investigating the acoustic emission activities during indentation toughness tests on an alumina based wear resistant ceramic and $25 \mathrm{wt} \%$ silicon carbide whisker $\left(\mathrm{SiC}_{\mathrm{w}}\right)$ reinforced alumina composite. It has been shown that the emitted acoustic emission signals characterize the crack growth during loading and unloading cycles in an indentation test. The acoustic emission results indicate that in the case of the composite the amount of crack growth during unloading is higher than that of loading, while the reverse is true in case of the wear resistant ceramics. Acoustic emission activity observed in wear resistant ceramic is less than that in the case of composite. An attempt has been made to correlate the acoustic emission signals with crack growth during indentation test.
\end{abstract}

Keywords. SiC whisker; alumina; composite; wear resistant ceramic; acoustic emission; indentation fracture toughness.

\section{Introduction}

Acoustic emission (AE) occurs in polycrystalline materials due to cooperative movement of slip dislocations, twinning, crack initiation and crack propagation (Ahmad et al 1990). But in case of brittle materials where the dislocation activity is less, the crack propagation can be clearly monitored by $\mathrm{AE}$ signals. The emission rage, $\mathrm{d} N / \mathrm{d} t$, is uniquely related to the fracture toughness $K_{\mathrm{IC}}$ for the propagating crack (Kohn and Ducheyne 1992). AE provides the ability to spatially and temporarily locate multiple cracks in real time. Changes in AE event also correspond to changes in crack extension rate, and may therefore be used to predict failure. AE offers two distinct advantages over conventional optical and microscopic methods of analyzing cracks. This technique being more sensitive can determine the time history of damage propagation (Porter and Chokshi 1987). It can also be employed to understand the cracking behaviour in ceramic materials during various mechanical tests for evaluating toughness properties.

Among various structural ceramics, $25 \mathrm{wt} \% \mathrm{SiC}$ whisker reinforced alumina composite has a potential application in the production of structural components used at elevated temperatures (Porter and Chokshi 1987; Ahmad et al 1990) in high efficiency heat engines and heat

*Author for correspondence recovery systems and for making cutting tools to machine special materials. When used in such applications, these ceramic components would often encounter monotonic and cyclic loading which produces crack extension. Becher and Wei (1984) reported that whisker orientation during processing of hot pressed $\mathrm{SiC}$-whisker reinforced alumina leads to anisotropy in both fracture toughness and fracture strength of the composites. In other words, their fracture strengths are limited by the non-uniformity of the distribution of the whiskers i.e. by the ability to disperse the $\mathrm{SiC}$ whiskers. They also found that the distribution of the whiskers improved by using finer alumina powder and hence an increase in the fracture strength of the composite was observed. The whiskers were preferentially aligned perpendicular to the hot pressing axis (Becher and Wei 1984; Wei and Becher 1985). This type of orientation of whiskers suggested that a great deal of arrangement of whiskers and powder occurred in the initial stage of densification of the composites and/or the matrix material underwent considerable deformation or creep during hot pressing. The fatigue crack growth rate and the fracture toughness both by indentation as well as by four-point bend test as per ASTM STP 410 (Ray et al 1994, 1996; Ray 1998) have been reported. The fractographic features of fatigue and fractured regions were discussed earlier (Ray et al 1995). The wear resistant alumina based ceramic is used as lining material in the areas of high erosion and abrasion 
environment particularly under impact fatigue loading viz. material handling equipments of thermal power, iron and steel, cement, coal washeries and other related industries. Impact fatigue properties of this material has been reported by Ray et al (1997). Baudin et al (1987) studied the fracture behaviour of a mullite-aluminazirconia composite by fractography and acoustic emission during indentation tests. Zhe et al (1987) studied the fracture toughness and acoustic emission activity of a pressureless sintered $\mathrm{Si}_{3} \mathrm{~N}_{4}$ material using the indentation method. They had observed its fracture toughness to be controlled by pore distribution. AE and SEM helped them explain the cracking manner. Yamanaka (1985) examined the subsurface cracks in various ceramics (introduced by Vickers indentation) by acoustic microscopy. The average length and initiation probability of subsurface lateral cracks were measured from acoustic images and found to depend more significantly on the material used than those of surface breaking radial cracks. The ratio of fracture toughness $K_{\mathrm{C}}$ for lateral fractures to fracture toughness $K_{\mathrm{IC}}$ for radial fracture also varied depending on the material used. The results revealed the difference in basic mechanisms of lateral and radial fractures in ceramics. Indentation method and $\mathrm{AE}$ technique were also used by Rouby and Osmani (1988) to characterize interface debonding in a unidirectional $\mathrm{SiC}$ (nicalon)/mullite composite $(0.33 \mathrm{vol}$ fraction of fibre). They have found the debonding mechanism to be governed by the energy release rate and not by a local failure criterion.

In the present paper, we have investigated $\mathrm{AE}$ signals generated during indentation toughness testing of alumina based composite and $25 \mathrm{wt} \% \mathrm{SiC}_{\mathrm{w}}$ reinforced $\mathrm{Al}_{2} \mathrm{O}_{3}$ composite. An attempt has been made to correlate the emitted AE signals with the crack growth during loading and unloading of the indenter in indentation test. The test results may therefore enable us to study as to how the material would behave during such tests with respect to the crack growth using $\mathrm{AE}$ signals.

\section{Experimental}

\subsection{Material}

The ceramic composite specimens used in this investigation were supplied by the National Institute of Standards and Technology (NIST), USA. These specimens were prepared by mixing $\alpha$-alumina powder of particle size $<1 \mu \mathrm{m}$ with $\beta$-SiC whisker (Krause et al 1990). The average diameter of the whisker is $0.45-0.65 \mu \mathrm{m}$ and the length ranges from $10-80 \mu \mathrm{m}$. This was hot pressed at $1700^{\circ} \mathrm{C}$ to $1850^{\circ} \mathrm{C}$ under a pressure of $25 \mathrm{MPa}$ for $30 \mathrm{~min}$ to produce a preferred billet. The grain size of the matrix varied between 1 and $6 \mu \mathrm{m}$. However, majority of the alumina grain size was in the range $2-4 \mu \mathrm{m}$ (figure 1). Details of fabrication, processing and micro- structural characterization are reported elsewhere (Ray et al 1995, 1996). Alumina based wear resistant ceramic was prepared at NML by wet mixing raw materials in the form of high purity calcined alumina having $\mathrm{Al}_{2} \mathrm{O}_{3}$ content of $99.9 \mathrm{wt} \%$, a minimum content of $\alpha-\mathrm{Al}_{2} \mathrm{O}_{3}$ of $85 \mathrm{wt} \%$ and an average particle size of $6-8 \mu \mathrm{m}$ was the major raw material used in this investigation. The hydraulically pressed samples were finally sintered at $1450^{\circ} \mathrm{C}$. In both the materials specimen of size $3 \mathrm{~mm} \times 4 \mathrm{~mm} \times 50 \mathrm{~mm}$ were made from the billet. The composite material had a porosity of $4.89 \%$, Young's modulus of $340 \mathrm{GPa}$ and a fracture strength of $559 \mathrm{MPa}$, as determined by NIST, USA, and reported in Krause et al (1990).

The montage of the ceramic composite revealed the 3D-distribution pattern of the whiskers in the longitudinal (L), long transverse (LT) and short transverse (ST) planes (figure 1). In the L plane, the whiskers appeared to be randomly oriented as the hot pressing direction was perpendicular to the L plane, and got further oriented thus producing the random orientation of the whiskers. Since maximum material flow occurred along the LT planes during hot pressing, the whiskers tended to get oriented parallel to the $\mathrm{L}$ plane. In the ST plane, there was a mixture of random orientation as well as normal alignment of the whiskers. Indentation tests were conducted on LT plane (figure 1) for composite as well as for wear resistant ceramic.

\subsection{Indentation fracture toughness tests}

Indentation tests were carried out using a Vickers Hardness Testing Machine on the $3 \mathrm{~mm} \times 50 \mathrm{~mm}$ faces of

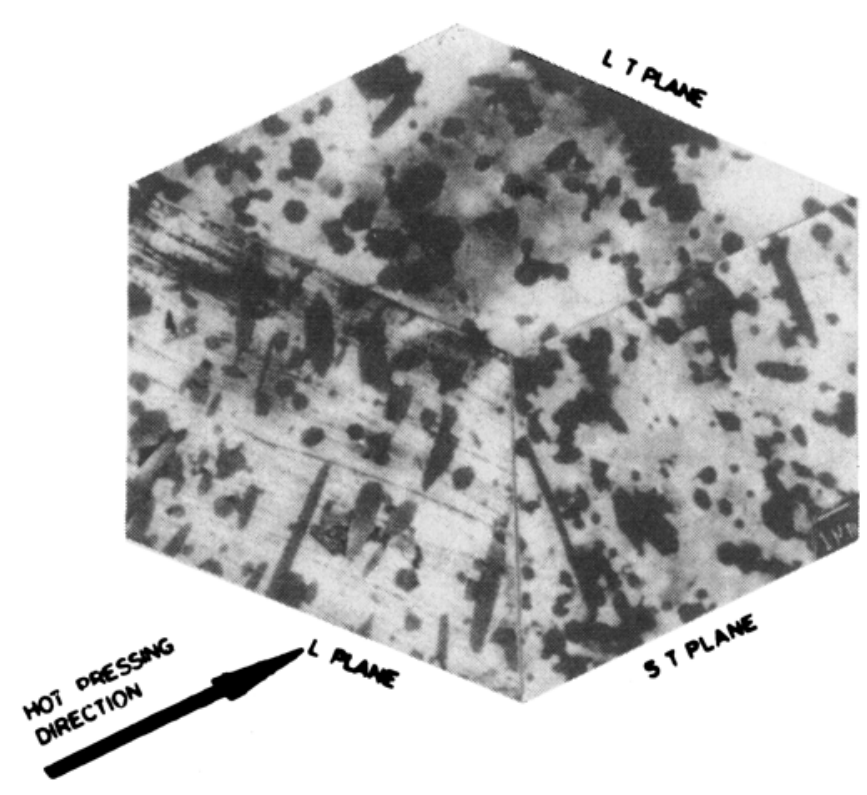

Figure 1. Montage of the microstructures of $25 \mathrm{wt} \% \mathrm{SiC}$ whisker reinforced alumina composite showing the distribution of whiskers along three planes. 
the specimen at three different loads of $0.63,0.8,1.0$ and $1.2 \mathrm{kN}$ for the composite and at $0.3,0.4,0.5$ and $0.6 \mathrm{kN}$ for the wear resistant ceramic. The corresponding crack lengths are reported in table 1 . The whole period of test for composite material and wear resistant ceramics were $\sim 200 \mathrm{sec}$ and $16-19 \mathrm{sec}$, respectively. After indenting the specimen, the hold time of the load is $100 \mathrm{sec}$ after loading and $\mathrm{AE}$ readings were taken for another $100 \mathrm{sec}$ after unloading for the composite. Since the wear resistant ceramic is less tough compared to the composite, our previous experience on the wear resistant ceramic has shown no AE signals generated after $20 \mathrm{sec}$. Therefore in the second set of experiments carried out on the wear resistant ceramic, the whole period was restricted within $20 \mathrm{sec}$.

AE signals were monitored during entire loading and unloading periods. Before indentation, the specimens were coated with aluminium in a vacuum evaporator by physical vapour deposition technique to about $0.02 \mu \mathrm{m}$ thickness, to facilitate location of the crack tip in SEM. The indentation fracture toughness of the ceramic composite was determined with Vickers indentation at various indentation loads of $0.63,0.8,1.0$ and $1.2 \mathrm{kN}$ using the following equation proposed by Anstis et al (1981) for toughened composite ceramics:

$$
K_{\mathrm{c}}=0.016 \sqrt{\left(\frac{E}{H}\right)} \cdot \frac{P}{a^{3 / 2}},
$$

where $E$ is the Young's modulus in GPa, $H$ the hardness in $\mathrm{GPa}, P$ the indentation load in $\mathrm{g}$, and $a$ the crack length in $\mu \mathrm{m}$. For the alumina based wear resistant ceramic, $K_{\mathrm{c}}$ was determined also by indentation technique at various loads of $0.3,0.4,0.5,0.6 \mathrm{kN}$ using the following equation for Palmqvist cracks (Ponton and Rawlings 1989):

$$
K_{\mathrm{c}}=0.0824 \frac{P}{a^{3 / 2}} .
$$

The Palmqvist cracks were measured with the help of micron marker in scanning electron microscope (SEM).

\subsection{Acoustic emission tests}

The equipment used to monitor acoustic emission in the experiment was a Spartan AT system from Acoustic Corporation, USA. A miniature piezoelectric transducer (PZT) with an operating frequency of $100-1000 \mathrm{kHz}$ and resonant at $125 \mathrm{kHz}$ was placed at one end of the specimen. The signals from the PZT were amplified and band pass filtered by a $40 / 60 \mathrm{~dB}$ preamplifier having $100-1200 \mathrm{kHz}$ band pass filter. The signals were then fed into the Spartan AT system. A fixed threshold of $40 \mathrm{~dB}$ and a system gain of $30 \mathrm{~dB}$ were used in the experiment. The results were directly visible on the computer screen and the acoustic emission plots were obtained on a printer attached to the computer system. The experimental set up is shown in figure 2. AE activity was recorded only for some selected loads in order to understand the cracking behaviour during indentation.

\section{Results}

Figure 3 shows that the nature of crack generated at the four corners of indentation in the $25 \mathrm{wt} \% \mathrm{SiC}$ alumina composite is Palmqvist indentation crack (Evans and Linzer 1973; Ponton and Rawlings 1989), since the summation of crack lengths in each indentation followed a linear relationship with the applied load. Similar observation of Palmqvist cracking was also observed in alumina based wear resistant ceramic. During indentation toughness testing, the relative fraction of crack growth was estimated based on the acoustic emission count accumulation during loading as well as unloading. Figure 4 shows the fractograph obtained from indentation cracked specimen of the wear resistant ceramic, exhibiting intergranular fracture with mullite needles interspersed in the fractograph. The sample fractured at a load of $0.6 \mathrm{kN}$.

The results of indentation fracture toughness are shown in figure 5 and table 1 . It indicates that the variation

Table 1. Indentation fracture toughness $\left(K_{c}\right)$ data generated for the materials under present investigation.

\begin{tabular}{llccc}
\hline Material & $\begin{array}{c}\text { Load } \\
(\mathrm{kN})\end{array}$ & $\begin{array}{c}\text { Crack length } \\
(\mathrm{mm})\end{array}$ & $\begin{array}{c}K_{\mathrm{c}} \\
(\mathrm{MPa} \sqrt{\mathrm{m}})\end{array}$ & $\begin{array}{c}K_{\mathrm{c}} \text {, average } \\
(\mathrm{MPa} \sqrt{\mathrm{m}})\end{array}$ \\
\hline 25 wt\% SiC reinforced & 0.63 & 0.39 & 5.37 & $5.48 \pm 0.08$ \\
alumina composite & 0.8 & 0.45 & $5 \cdot 45$ & \\
& 1.0 & 0.52 & $5 \cdot 50$ & \\
& 1.2 & 0.57 & 5.60 & \\
Alumina based wear & 0.3 & 0.42 & 2.85 & $3.09 \pm 0.30$ \\
resistant ceramic & 0.4 & 0.49 & 3.05 & \\
& 0.5 & 0.55 & 3.20 & \\
& 0.6 & 0.61 & 3.28 & \\
\hline
\end{tabular}


of $K_{\mathrm{c}}$ vs $a$ (square root of crack length) yielded a positive slope. This is indicative of a certain amount of compressive residual stress being present in the material. A similar trend was also observed by Baudin et al (1987). The average crack length of the cracks emanating

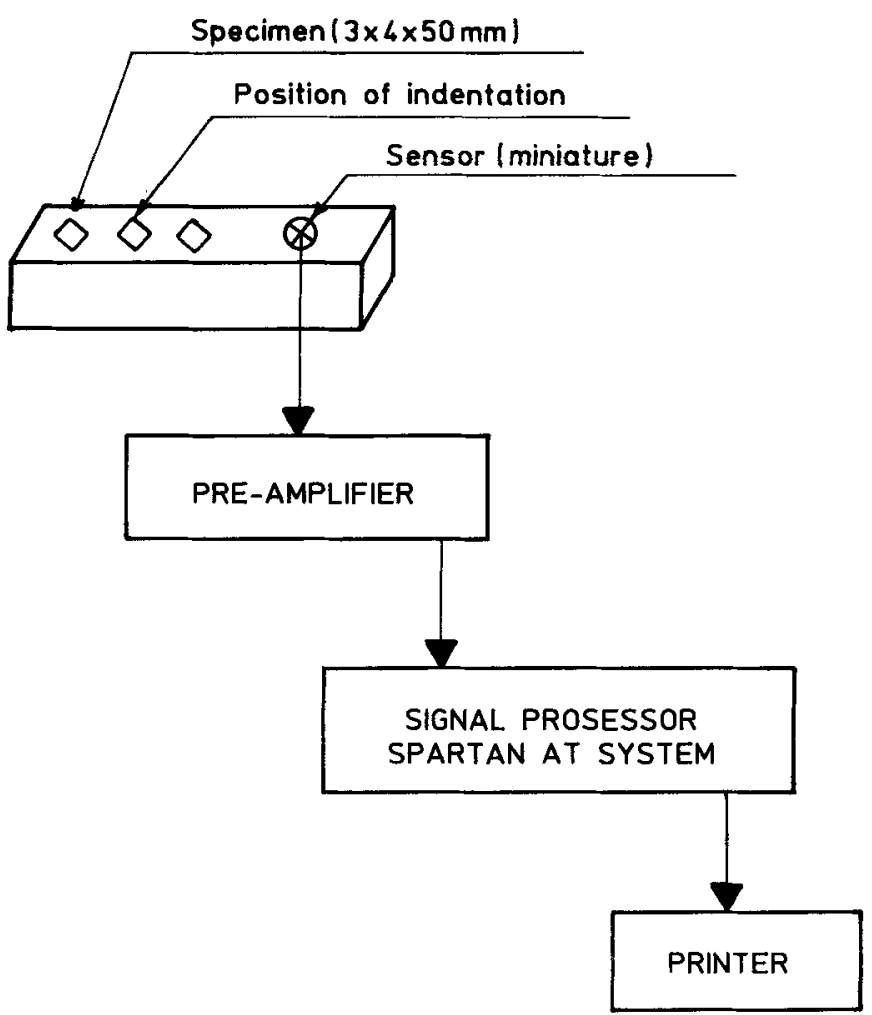

Figure 2. Schematic diagram showing the experimental set-up for indentation test using acoustic emission technique.

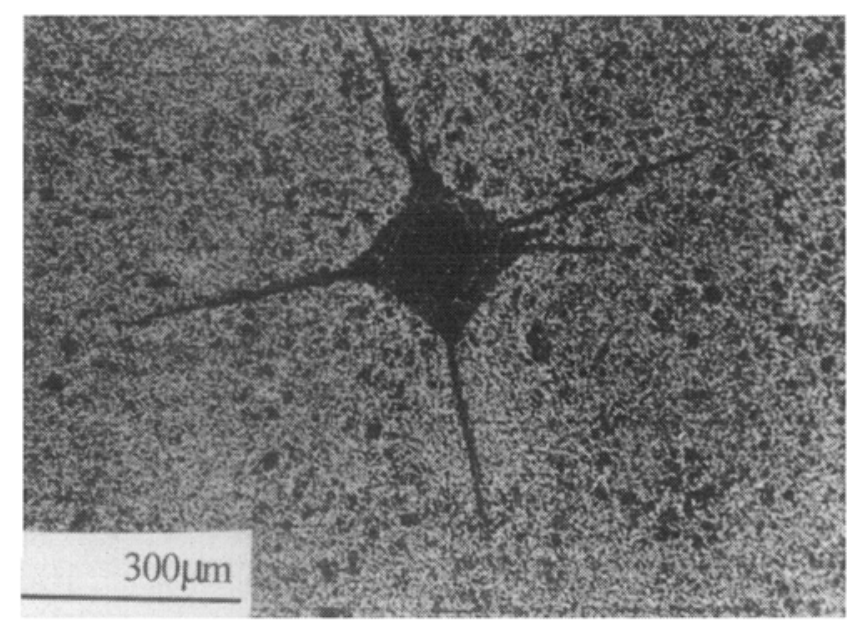

Figure 3. Cracks developed at four corners of the indentation in a $25 \mathrm{wt} \% \mathrm{SiC}$ reinforced alumina composite. from the four corners of indentation is reported in table 1. The crack length was measured with the help of micron marker in the SEM-JEOL 840A. The average indentation fracture toughness value for the composite and wear resistant ceramic are well in agreement with that reported by Kraus et al (1990) and Ray et al (1997), respectively.

Acoustic emission activity during the entire period of the indentation tests for all the above mentioned load levels (five tests at each load level) were obtained and the average cumulative $\mathrm{AE}$ counts for each load level was computed as an arithmetic mean of the five tests. The results are given in tables $2 \mathrm{a}$ and $\mathrm{b}$ for composite and wear resistant ceramic, respectively. The cumulative $\mathrm{AE}$ counts as a function of time, representing at various loads level, were plotted for composite and wear resistant ceramic, and are shown in figures $6 \mathrm{~b}, \mathrm{~d}$ and $\mathrm{f}$ and figures $6 h, j$ and $l$, respectively. The nature of the curve for all the five tests at a given stress level was similar.

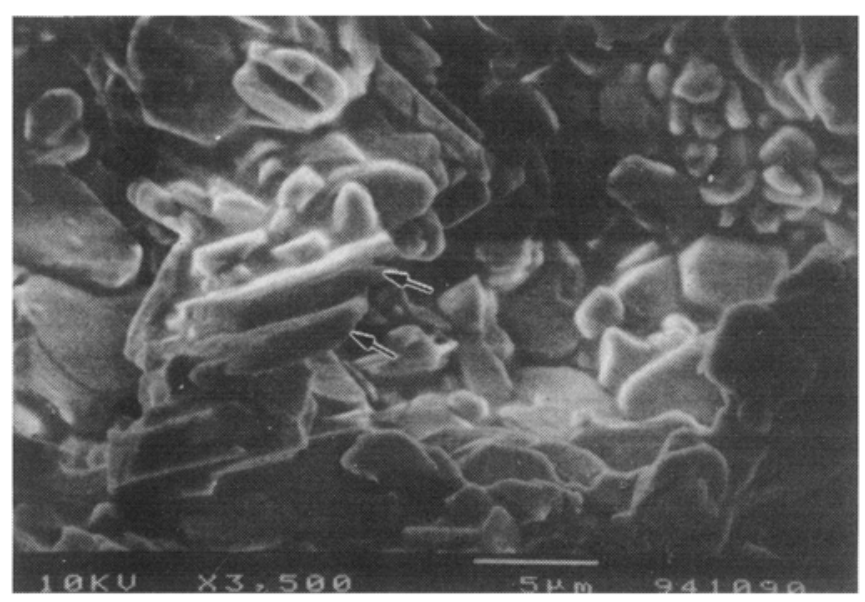

Figure 4. Fractograph of the alumina based wear resistant ceramic showing needle like mullite phase (indicated by arrow) randomly oriented in $\mathrm{Al}_{2} \mathrm{O}_{3}$ matrix.

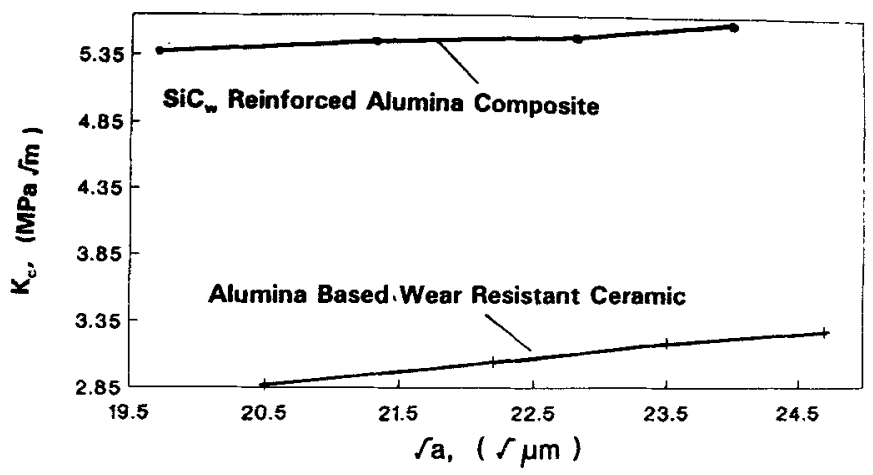

Figure 5. Dependence of indentation fracture toughness $K_{\mathrm{c}}$ on the square root of crack length $\sqrt{a}$. 
Table 2a. Cumulative ring down counts data of acoustic emission of $25 \mathrm{wt} \% \mathrm{SiC}$ reinforced alumina composite.

\begin{tabular}{|c|c|c|c|c|c|c|}
\hline \multirow[b]{2}{*}{$\begin{array}{l}\text { Sl. } \\
\text { no. }\end{array}$} & \multirow[b]{2}{*}{$\begin{array}{l}\text { Load } \\
(\mathrm{kN})\end{array}$} & \multicolumn{5}{|c|}{ Cumulative ring down counts } \\
\hline & & $\begin{array}{l}\text { Whole period } \\
200 \mathrm{sec}(\text { Avg. X) }\end{array}$ & $\begin{array}{l}\text { Loading } \\
\text { (Avg. Y) }\end{array}$ & $\begin{array}{l}\text { Unloading } \\
\text { (Avg. Z) }\end{array}$ & $\begin{array}{l}Y / X \\
(\%)\end{array}$ & $\begin{array}{l}Z / X \\
(\%)\end{array}$ \\
\hline 1 & $0 \cdot 6$ & 2758 & 1096 & 1662 & 40 & 60 \\
\hline 2 & $1 \cdot 0$ & 3436 & 612 & 2823 & 18 & 82 \\
\hline 3 & $1 \cdot 2$ & 3543 & 1600 & 1941 & 45 & 55 \\
\hline
\end{tabular}

Table 2b. Cumulative ring down counts data of acoustic emission of alumina based wear resistance ceramic.

\begin{tabular}{|c|c|c|c|c|c|c|}
\hline \multirow[b]{2}{*}{$\begin{array}{l}\text { S1. } \\
\text { no. }\end{array}$} & \multirow[b]{2}{*}{$\begin{array}{l}\text { Load } \\
(\mathrm{kN})\end{array}$} & \multicolumn{5}{|c|}{ Cumulative ring down counts } \\
\hline & & $\begin{array}{c}\text { Whole period } \\
16-19 \mathrm{sec} \\
\text { (Avg. X) }\end{array}$ & $\begin{array}{l}\text { Loading } \\
\text { (Avg. Y) }\end{array}$ & $\begin{array}{l}\text { Unloading } \\
\text { (Avg. Z) }\end{array}$ & $\begin{array}{l}Y / X \\
(\%)\end{array}$ & $\begin{array}{l}Z / X \\
(\%)\end{array}$ \\
\hline 1 & 0.4 & 8560 & 8290 & 270 & 96.8 & 3.2 \\
\hline 2 & 0.5 & 665 & 625 & 40 & 94 & 6 \\
\hline 3 & 0.6 & 24000 & 20000 & 4000 & 83 & 17 \\
\hline
\end{tabular}

The amplitude distribution for $\mathrm{AE}$ tests are shown in figures $6 \mathrm{a}, \mathrm{c}$ and $\mathrm{e}$ for composite and in figures $6 \mathrm{~g}, \mathrm{i}$ and $\mathbf{k}$ for wear resistant ceramic. It is seen from table $2 a$ and figures $6 \mathrm{~b}, \mathrm{~d}$ and $\mathrm{f}$, that the cumulative acoustic emission counts generated during unloading of the indenter in the composite is higher than that of loading. The acoustic emission activity during unloading is more than $50 \%$ of the total activity, whereas during loading it is less than $50 \%$ of the total activity. Even though observation was based on an average of five tests at each load level, there was some scatter on test results, which possibly could be due to the inhomogeneity of the composite (figure 1). Here the signal amplitude for all the load levels as shown in figures $6 a, c$ and $e$ were between 40 and $80 \mathrm{~dB}$. Whereas for wear resistant ceramic, most of the AE signals were generated during loading and very less AE signals were generated during unloading (see table $2 b$ and figures $6 h, j$ and $k$ ). The signal amplitudes for this material were also between 40 and $80 \mathrm{~dB}$ (figures $6 \mathrm{~g}, \mathrm{i}$ and $\mathrm{k}$ ). The horizontal portion of the counts vs time plots (figures $6 \mathrm{~b}, \mathrm{~d}, \mathrm{f}, \mathrm{h}$, $\mathrm{j}$ and 1) represent the hold period. The first increase in count showed load increase during loading and the second increase in count showed unloading. Total indentation period for the composite was $200 \mathrm{sec}$ and that for the wear resistant ceramic it varied between only 16 and $19 \mathrm{sec}$ (figure 6). This was because the indentation fracture toughness of the wear resistant ceramic was lower than that of the composite (figure 5, table 1) and the wear resistant ceramic fractured at $0.6 \mathrm{kN}$ load (figure 4).

\section{Discussion}

A residual compressive surface stress would decrease the surface crack length, while a residual tensile surface stress would do the reverse. There are various ways in which surface stresses could be introduced into a material; of particular relevance to the production of samples for indentation testing is the process of surface grinding of brittle materials, e.g. using $\mathrm{SiC}$ or diamond abrasive wheels on glass, ceramics and cermets (Lange et al 1983). It is well documented that this surface finishing method induces residual stresses in materials such as alumina (Lange et al 1983), polyceram C906 glassceramic (Cook et al 1981) and zirconia-toughened alumina (Green et al 1983). If the slope of $K_{\mathrm{c}}$ vs $a$ is positive it indicates that the nature of residual stress present is compressive but if the slope is negative, then tensile residual stresses are present (Marshall et al 1977; Ikuma and Virakar 1984; Ray et al 1996). Marshall and Lawn (1977) showed that such plots for tempered soda-lime glass plate produced a positive slope indicating that the nature of residual stress is compressive. In line with Marshall and Lawn (1977) model, Ikuma and Virakar (1984) thus concluded that a positive linear dependence of indentation fracture toughness with square root of crack length for the transformation-toughenable ceramics indicates the presence of residual surface compressive stresses induced by the tetragonal to monoclinic transformation of $\mathrm{ZrO}_{2}$ or $\mathrm{HfO}_{2}$ particles in the near-surface layers upon surface grinding. Figure 5 clearly infers that in the current study, the nature of residual stresses 
present in the composite is compressive as confirmed by indentation technique. It had been well explained that considerable local branching at the corners of the indentation and small amount of deflection gave rise to the appearance of local curvature in the crack path and this could partly account for the rising trend in the $K_{\mathrm{c}}$ values (Kraus et al 1990; Ray et al 1994, 1996; Ray 1998). This branching behaviour and crack deflection observed could also be explained in terms of grain-bridging phenomenon associated microstructural toughening (Kraus et al 1990; Ray et al 1995). Possibly, on the scale of grain sizes, the grains of alumina were entangled
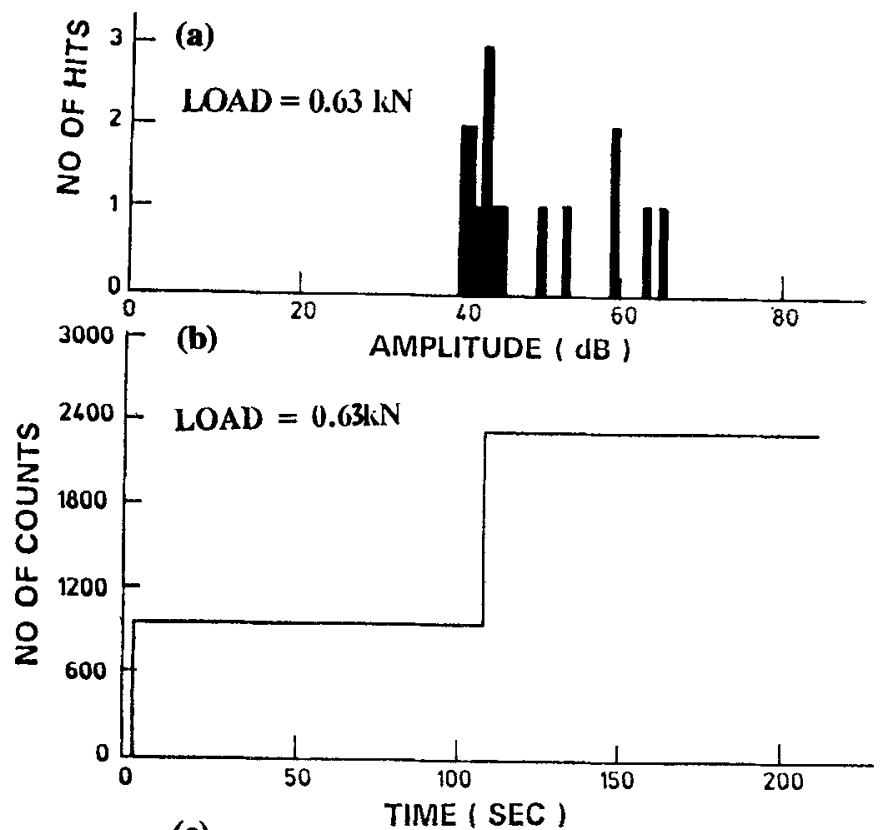

(c)

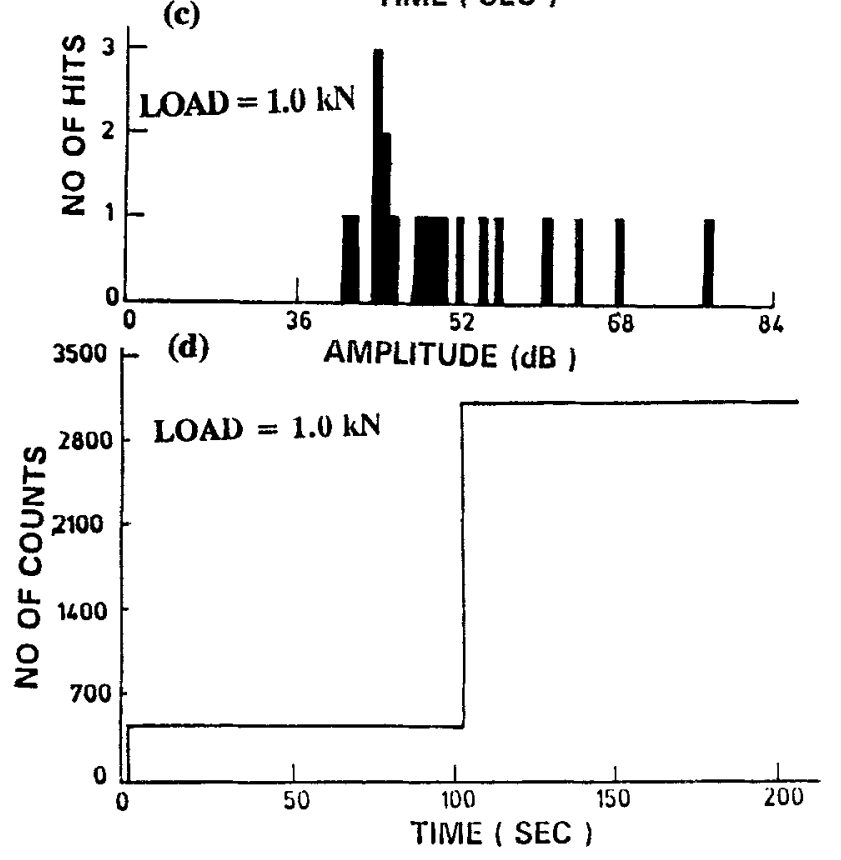

Figure 6. a-d. with the SiC whiskers in such a way that, because of a complex residual stress field, high resistance to crack propagation was created and hence the crack tended to find a new starting point at the weakest area away from this region. Also, because of smaller linear coefficient of the $\mathrm{SiC}$ particles relative to the alumina matrix, large residual stress developed in the alumina phase upon cooling from the hot pressing temperature $\left(1700-1850^{\circ} \mathrm{C}\right)$ and thus it was likely to produce dislocations around the interface of $\mathrm{SiC}$ particle with the matrix. The network of dislocations around a particle could deflect a crack to paths of lower energy (Ray et al 1994, 1995, 1996).
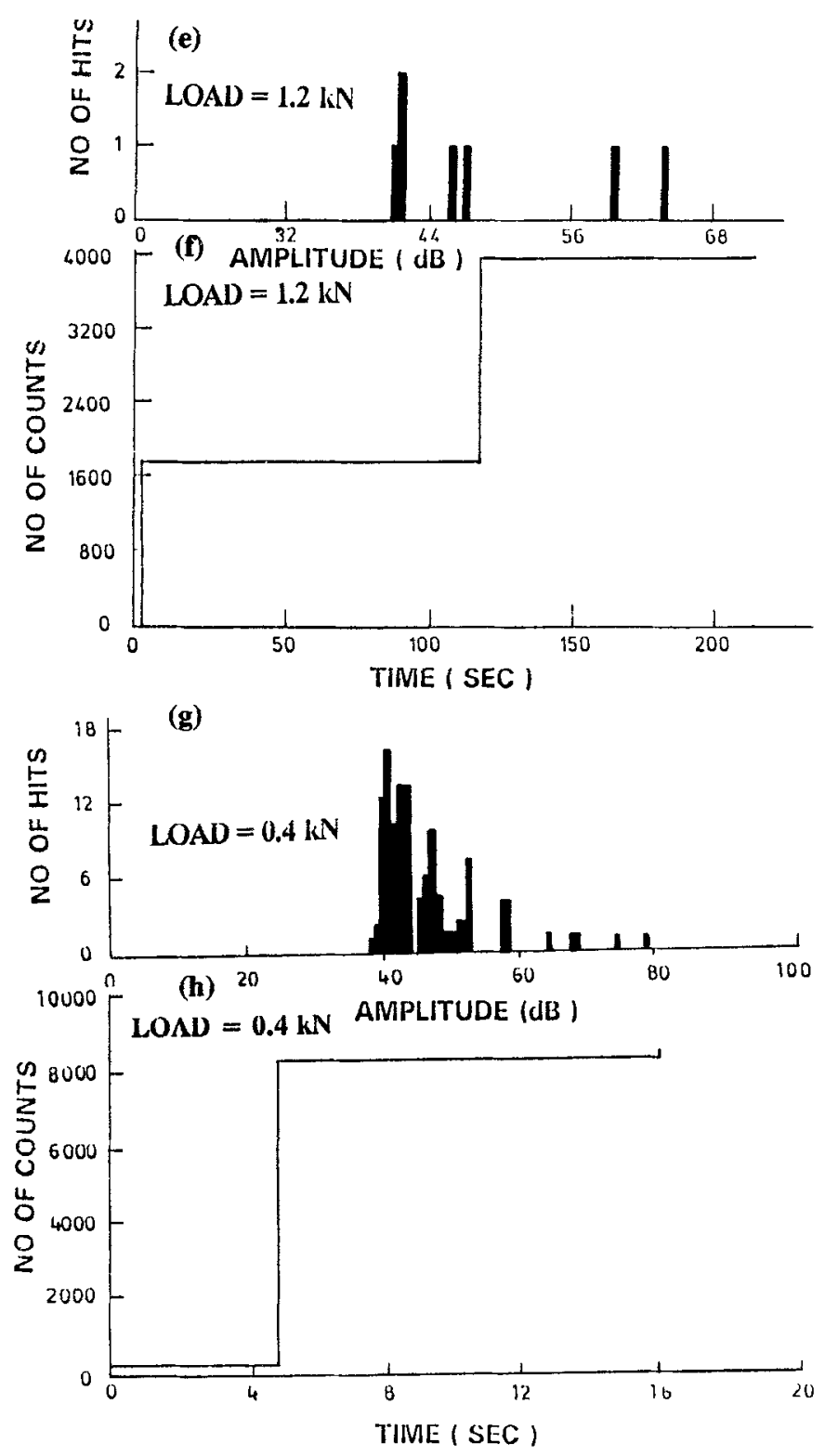

Figure 6. e-h. 
It is well established that (Becher and Wei 1984; Ray et al 1996) whisker orientation during processing of hot pressed $\mathrm{SiC}$ reinforced alumina leads to anisotropy in both fracture toughness and fracture strength of the composite. The composite is toughened by grain bridging phenomenon of the whiskers (Ray et al 1995, 1996; Ray 1998). It could be clearly seen in figure 2 that in the $\mathrm{L}$ (longitudinal) plane where indentation test was carried out, the whiskers are randomly oriented and therefore there was large scatter between the individual tests. For $25 \mathrm{wt} \% \mathrm{SiC}_{\mathrm{w}}$ reinforced alumina composite the

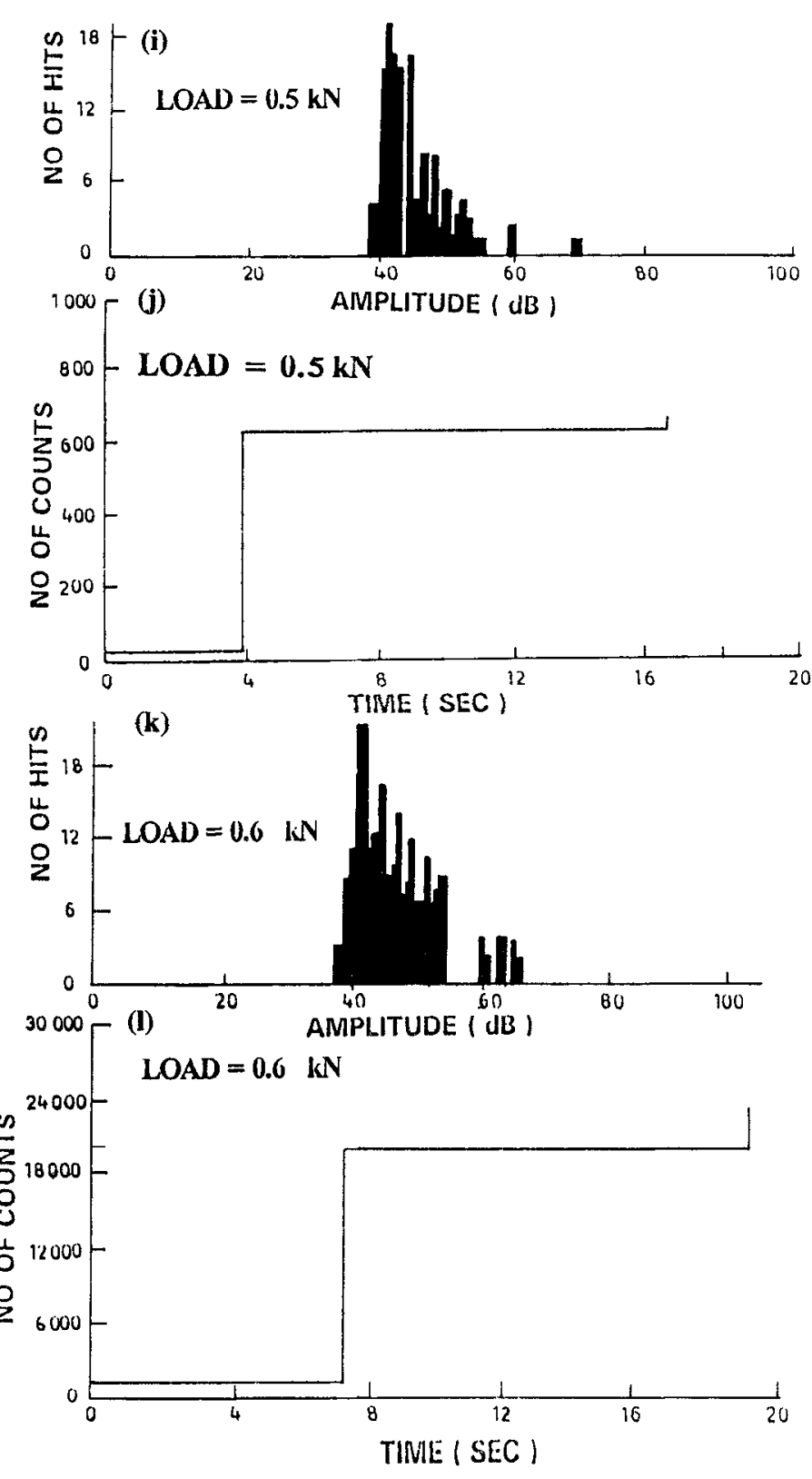

Figure 6. AE activities during indentation tests at various loads. (a-f) for composite and (g-1) for wear resistant ceramic, respectively. amount of crack growth during unloading was higher than that of loading, confirmed by AE activity. This is possibly because, during loading, the free surface of the plastically deformed zone surrounding the indenter is under tensile hoop stress, while at constant load the free surface of the elastically deformed zone surrounding the plastic zone is under compressive stress. When the indenter is unloaded, the compressive elastic strain is removed and the crack growth continues being driven by tensile stress. Crack growth occurs just during loading and unloading of the indenter and hold time has no effect on crack growth. From figures $6 b$, $d$ and $f$, it could be seen that signal amplitude for all the load levels are between 40 and $80 \mathrm{~dB}$ and no $\mathrm{AE}$ activity was observed during hold time of loading and unloading, which was observed by Baudin et al (1987) on mullite-alumina-zirconia composite. They had carried out indentation and $\mathrm{AE}$ studies on mullite-aluminazirconia composite. According to them, for lower load $(0.31 \mathrm{kN})$, acoustic signals were observed only during loading and unloading whereas, no acoustic signals were observed when the indenter was at constant load. But in case of a higher maximum load of $0.4 \mathrm{kN}, \mathrm{AE}$ activity was observed during loading and at constant load, but were not observed during unloading.

For the alumina based wear resistant ceramic which is relatively less tough, less $\mathrm{AE}$ activity was observed in indentation. During indentation test, most of the $\mathrm{AE}$ signals were generated under loading condition, hold time did not produce any detectable AE signals while unloading condition generated very less $\mathrm{AE}$ (figures $6 \mathrm{~g}-1)$. As the indentation load was increased, the number of $\mathrm{AE}$ hits also increased. In this ceramic, the needle like mullite phases are also randomly distributed in the matrix of alumina (figure 4). These phases actually resist crack growth. During loading, the crack propagation was fast, so the AE activity was high. Consequently, during fast propagation the accumulated residual stress energy gets accommodated along the low energy grain boundary leading to an intergranular fracture pattern (figure 4). This could be the possible explanation as to why only during loading $\mathrm{AE}$ activity was more pronounced in this ceramic. In other words crack propagation during unloading was slow so AE activity was very low.

\section{Conclusions}

The amplitude range of $\mathrm{AE}$ signals during indentation testing of $25 \mathrm{wt} \% \mathrm{SiC}_{\mathrm{w}}$ reinforced alumina composite and alumina based wear resistant ceramic were found between 40 and $80 \mathrm{~dB}$, which appears similar in both the cases. For the composite, the amount of crack growth during unloading is found to be higher than that during loading, causing more $\mathrm{AE}$ signals during unloading. The reverse is true in the case of wear resistant ceramic. In 
both the cases, hold time after loading has no effect on crack growth which is evident from the absence of $\mathrm{AE}$ activity.

\section{References}

Anstis G R, Chantikul P, Lawn B R and Marshall D B 1981 J. Am. Ceram. Soc. 64544

Ahmad C Salomah and Reichert Wolfgand $1990 \mathrm{~J}$. Am. Ceram. Soc. 73740

Baudin C, Cambier F and Delney L 1987 J. Mater. Sci. 22 4398

Becher P F and Wei G C 1984 J. Am. Ceram. Soc. 67267

Cook R F, Lawn B R, Dabbs T P and Chantikul P $1981 \mathrm{~J}$. Am. Ceram. Soc. $64 \mathrm{C} 121$

Evans A G and Linzer M $1973 \mathrm{~J}$. Am. Ceram. Soc. 56575

Green D J, Lange F F and James M R $1983 \mathrm{~J}$. Am. Ceram. Soc. 66623

Ikuma Y and Virakar A V 1984 J. Mater. Sci. 192223

Kohn D H and Ducheyne P 1992 J. Mater. Sci. 273133

Krause R F, Fuller Jr E R and Rhodes J F $1990 \mathrm{~J}$. Am. Ceram. Soc. 73559
Lange F F, James M R and Green D J $1983 \mathrm{~J}$. Am. Ceram. Soc. $66 \mathrm{Cl} 6$

Marshall D B and Lawn B R 1977 J. Am. Ceram. Soc. 6086

Ponton C B and Rawlings R D 1989 Br. Ceram. Trans. J. 88 83

Porter J R and Chokshi A H 1987 in Ceramic microstructure 86 (eds) J A Pask and A G Evans (New York: Plenum Press) p. 919

Ray A K 1998 J. Eur. Ceram. Soc. 181655

Ray A K, Banerjee S, Fuller Jr E R, Das S K and Das G 1994 Bull. Mater. Sci. 17101

Ray A K, Das S K, Roy P K and Banerjee S 1995 J. Eur. Ceram. Soc. 15191

Ray A K, Fuller Jr E R and Banerjee S 1996 J. Eur. Ceram. Soc. 16503

Ray A K, Das S K, Maity S, Mukhopadhyay N K, Tarafdar S and Dwarakadasa E S 1997 Interceram. 46184

Rouby D and Osmani H 1988 J. Mater. Sci. Lett. 71154

Tiegs T N and Becher P T 1987 J. Am. Ceram. Soc. $70 \mathrm{C} 109$

Wei G C and Becher P F 1985 J. Am. Ceram. Soc. Bull. 64 298

Yamanaka K 1985 Jpn J. Appl. Phys. 24184

Zhe X, Wang C and Zhang H 1987 J. Mater. Sci. Lett. 61459 